\title{
The Future Nordic Co-operation on Health
}

\section{Bo Könberg}

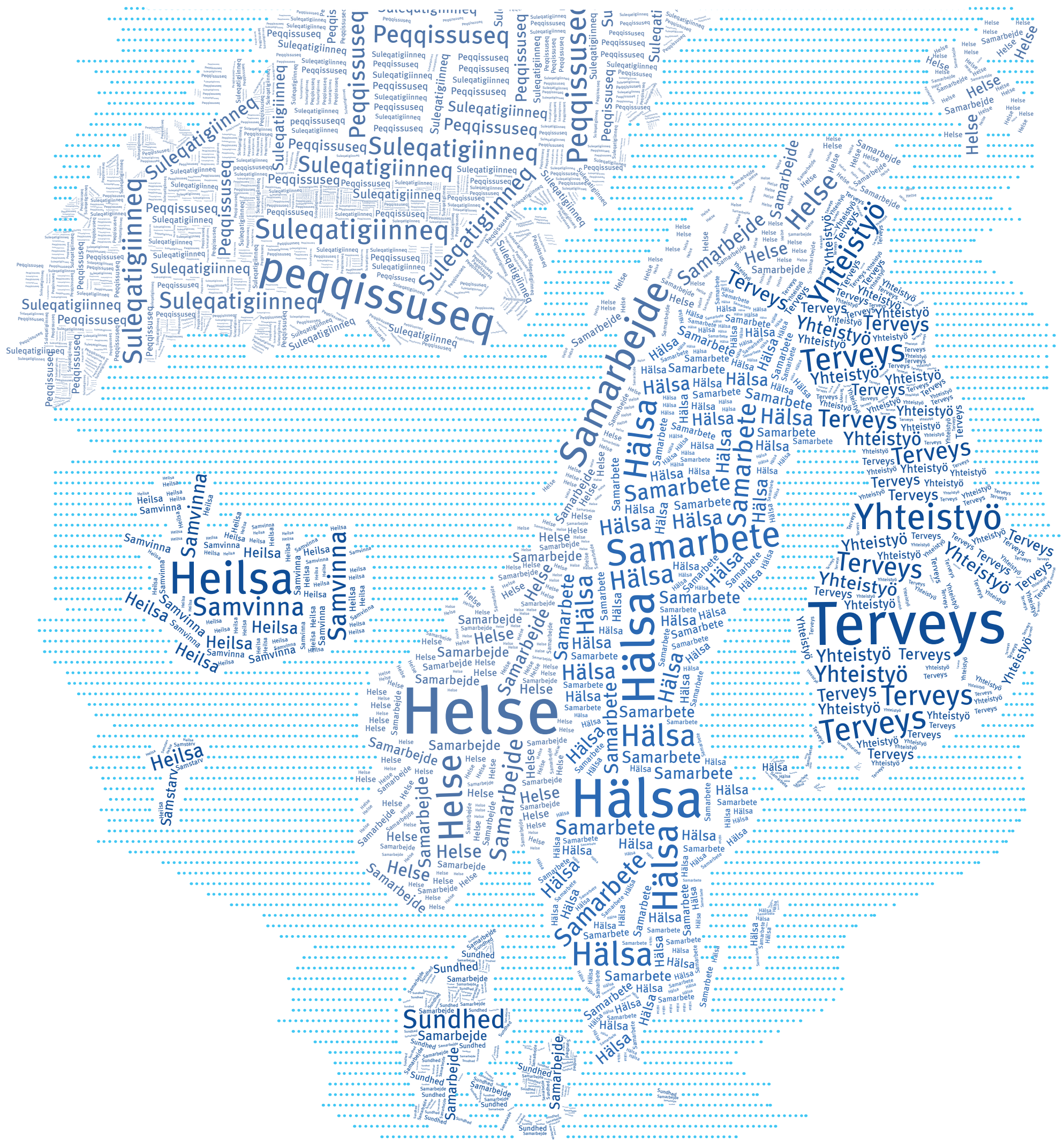




\section{The Future Nordic Co-operation on Health}

ISBN 978-92-893-2811-1

http://dx.doi.org/10.6027/ANP2014-731

ANP2014:731

(C) Nordic Council of Ministers 2014

This publication has been published with financial support by the Nordic Council of Ministers. However, the contents of this publication do not necessarily reflect the views, policies or recommendations of the Nordic Council of Ministers.

www.norden.org/en/publications

Nordic Council of Ministers

Ved Stranden 18

DK-1061 Copenhagen K

Phone (+45) 33960200

www.norden.org

\section{Nordic co-operation}

Nordic co-operation is one of the world's most extensive forms of regional collaboration, involving Denmark, Finland, Iceland, Norway, Sweden, and the Faroe Islands, Greenland, and Åland.

Nordic co-operation has firm traditions in politics, the economy, and culture. It plays an important role in European and international collaboration, and aims at creating a strong Nordic community in a strong Europe.

Nordic co-operation seeks to safeguard Nordic and regional interests and principles in the global community. Common Nordic values help the region solidify its position as one of the world's most innovative and competitive. 


\section{The Future Nordic Co-operation on Health}

\section{Bo Könberg}

Introduction

Antibiotic resistance

Proposal 1 Vigorous measures against the increasing antibiotic resistance

Highly-specialised treatment

Proposal 2 Strong co-operation on highly-specialised treatment in the Nordic region

Rare diagnoses

Proposal 3 Set up Nordic network on rare diagnoses

Register-based research

Proposal 4 A Nordic virtual centre is set up for register-based research

Public health and inequalities in health

Proposal 5 Increased co-operation on initiatives to improve public health

Patient mobility

Proposal 7 Patient mobility within the Nordic region

Health and technology

Proposal 8 Strengthened co-operation on welfare technology

Proposal 9 Extended co-operation on e-Health

Psychiatry

Proposal 10 Stronger Nordic co-operation in the psychiatry area

Health preparedness

Proposal 11 Greater mandate for co-operation within the health preparedness area 26

Pharmaceuticals

Proposal 12 Extended Nordic pharmaceutical co-operation for greater cost-effectiveness and better safety

Exchanges for officials

Proposal 13 New exchange of Nordic officials - pilot project

National experts in the EU

Proposal 14 Nordic co-operation on national experts in the EU Commission 


\section{Introduction}

At the end of August last year, I was asked by the Secretary General of the Nordic Council of Ministers and the Nordic Ministers for Health and Social Affairs to write a report on stronger Nordic cooperation on health care. The proposals were to be implementable within 5-10 years. In terms of structure and scope of the report, the well-received report on Nordic foreign and security policy presented by Thorvald Stoltenberg in Oslo in February 2009 was cited as an example.

Meanwhile, each of the ministers have appointed two contact persons: Flemming Møller Mortensen and Sophie Løhde from Denmark, Ulla-Maija Rajakangas and Anne Louhelainen from Finland, Unnur Brá Konrádsdóttir and Árni Páll Árnason from Iceland, Cecilie Brein-Karlsen and Torgeir Micaelsen from Norway, and Lena Furmark and Lena Hallengren from Sweden. The contact persons have given valuable comments, but I have sole responsibility for the 14 proposals that are presented here.

The Nordic Council of Ministers Senior Adviser, Astrid Utterström, has assisted me throughout the period with all contacts and in production of the report.

I have also been in contact with Thorvald Stoltenberg and Sverre Jervell, who was one of the secretaries who helped Stoltenberg.

The work on my report has included two trips to each of the Nordic capitals, one trip to the Faeroes and one to Åland. The meeting with the minister for health from Greenland was held on the Faeroes. The total number of meetings was more than
80 , and involved approximately 250 people.

Interest for increased co-operation on health care has proved to be great, and I have been greatly helped by all the comments we have received during the meetings and in other contacts.

Health in the Nordic region is good. The average life expectancy in the Nordic region is over 80 years; all five countries are in the group of 25-26 countries with the longest life expectancy, and three of them are in the top 10 in terms of life expectancy. In addition, the rapidly increasing life expectancy seems to consist of healthy years. Infant mortality is among the lowest in the world, with all five countries among the group of 20 countries with lowest infant mortality, and four among the 5-6 lowest.

Some of my main impressions of the meetings and the contacts are as follows:

- All Nordic countries wish to extend and strengthen the co-operation in the health area.

- There is a widespread perception that the growing resistance to antibiotics requires vigorous action in the world.

- The countries have shown great interest in more co-operation on highly-specialised treatment.

- There is a widespread perception that the countries should co-operate more and better with register-based research.

- There is a widespread perception that psychiatric ill-health has increased in the Nordic region, not least among children and young people. 
- The countries have shown great interest in continued and extended co-operation on inequalities in health.

Apart from the above impressions, I also want to raise two important issues antibiotic resistance and patient mobility. One issue that arose at an early stage was how overuse and incorrect use of antibiotics has led to a very worrying increase in antibiotic resistance in the world. Since then, my concern about this development has only increased, and was reinforced by the first global report, presented by the World Health Organization (WHO) just over a month ago, and confirmed by the report on these issues presented by the joint EU-US body (TATFAR) a couple of weeks later.

Resistance to drugs is an ever-growing problem in the world; in addition to bacteria that have developed resistance to various types of antibiotics, the resistance situation regarding drugs against tuberculosis and malaria is also very alarming. Mortality due to both tuberculosis and malaria has been reduced in recent decades because of effective medicines, but now there is also an alarming increase in resistant and multi-resistant tuberculosis bacteria.

The worrying situation with regard to antibiotics and drugs against tuberculosis and malaria makes it vital, in my view, that the issue be considered by the Nordic ministers at a meeting during the autumn.

Patient mobility concerns the right of Nordic citizens to receive medical care in another country. The issue is managed, for example, for the EU members and
Norway and Iceland through the EU patient mobility directive. Very recently, decisions have been taken in the five Nordic countries about implementation of the directive. Naturally, it has not yet been possible to obtain any experiences of the outcome of implementation for the Nordic citizens.

Pending knowledge on how the Nordic patients' mobility is affected by the new - and partly differing - regulations in the five countries, I have refrained from proposing any further improvements; instead I propose that the issue be considered at a ministerial meeting next year.

A central issue, of course, is which health care issues will be managed better through Nordic co-operation. Here, an assessment must also be made of what could be managed even better at European level.

Using the various meetings and contacts, I have formulated 14 tangible proposals. They have been designed so that all Nordic countries could be involved. However, it may sometimes be the case that 3-4 countries continue and others can join later, or possibly not at all.

Reykjavik, 11 June 2014

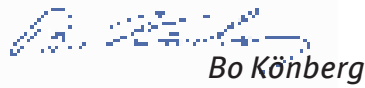




\section{Antibiotic resistance}

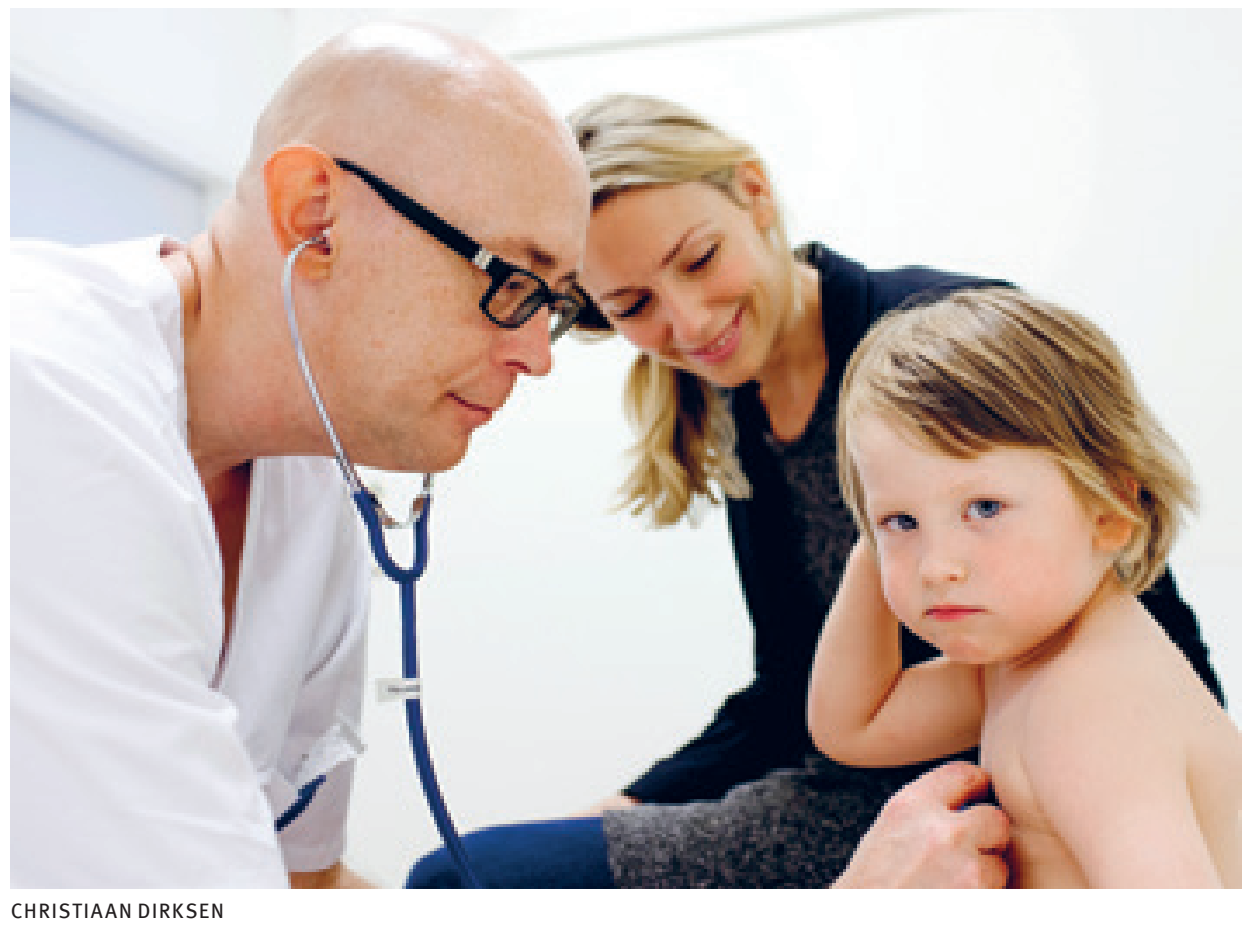

Proposal 1

\section{Vigorous measures against the increasing antibiotic resistance}

The Nordic region should emphatically push the issue of vigorous measures against the increasing antibiotic resistance and resistance to drugs against tuberculosis and malaria. Although the Nordic countries, on average, have lower antibiotic use than the rest of Europe, and of course are themselves responsible for a very small proportion of the world problem, they must set up their own targets to rapidly - in the next 5 years - reduce consumption of antibiotics to the lowest European level, which is currently that of the Netherlands.

Furthermore, the Nordic countries must, within the EU, WHO and UN, work for a rapid implementation of a programme against today's unreasonably high use of antibiotics, and to strengthen systems and co-operation structures that can help to develop new antibiotics and provide rewards for developing new antibiotics. Three points in the programme should be:

- Introduction of prescription requirement in the countries with health systems 
that are so developed that this is possible, and a stop to bonuses for doctors and hospitals that prescribe antibiotics. Also, stop veterinary surgeons from selling the antibiotics they prescribe.

- All countries should introduce regulations and targets to reduce their own use.

- Strong incentives for development of new antibiotics. In the coming 5 years, the rich countries should annually allocate SEK 15 billion to strengthening systems and co-operation structures that can help to develop new antibiotics, and for rewards to those who discover and develop new drugs of this type.

One of the biggest inventions in the 20th century was the discovery and the industrial manufacture of penicillin and other antibiotics against bacteria in the human body. The discovery was made over 80 years ago, and was awarded the Nobel Prize in Medicine in 1945. In his speech of thanks, one of the prize-winners, Sir Alexander Fleming, warned that the risk of overuse in the future could lead to the antibiotic losing its effect.

Such overuse and subsequent increased resistance to antibiotics has been going on for a long time. In Europe last year, at least 25,000 people died because resistance to antibiotics is spreading. In the same year, the number of people killed on the roads in Europe was the same. In USA, it was calculated a few weeks ago that the corresponding figure was over 23,000. In addition, discoveries of new antibiotics have, in practice, ceased. Up to 1970 , around twenty antibiotics had been developed. Since then, two have been developed, neither of them after 1987 !

And, as far as is known, no new discoveries are waiting round the corner. The news to us today is that there are no new antibiotics in the pipeline and, with current development, the probability is low that any new ones will appear in the next ten years.
Resistance to antibiotics leads to major problems in health care, because modern health care is completely dependent on antibiotics. What is starting to happen, and we will see more of this in the future, is increased mortality due to infections. This applies both to injuries like wounds or traffic injuries and also infections like pneumonia or urinary tract infections that we do not currently regard as dangerous because they can be treated with antibiotics. Many transplants and operations will become impossible or very risky, because in surgery antibiotics are given both preventively and after the intervention. In diseases that weaken the immune defence system, like cancer or $H I V$, it is often an infection that cannot be stopped that is the cause of death.

Attention has been drawn to this very worrying development before, such as by WHO over ten years ago but, despite this, far from sufficient measures have been taken. At the end of April, WHO presented its first global report on the increasing antimicrobial resistance to antibiotics and to drugs against tuberculosis and malaria. The content is very alarming. A couple of weeks later, the joint EU-USA body (TATFAR) also presented a report on the worrying development.

In addition to resistance to antibiotics, the resistance is also very alarming with regard to drugs against tuberculosis and malaria. In recent decades, mortality due to both tuberculosis and malaria could be reduced because of effective medicines, but now there is also a rapid increase in resistance to these medicines.

It should now be apparent to everyone that extremely rapid measures must be taken to reduce consumption and thereby give us some more time in which we must develop new antibiotics, and hasten this by ensuring there are powerful financial incentives to develop them.

Overconsumption in the Nordic region and the rest of Europe is very probably 
less than in China, India and USA, but it must nevertheless be reduced of course both to help reduce the rate of increasing resistance and to more vigorously influence the rest of the world to reduce its consumption.

A common way to measure the scale is the number of doses per day and thousand population. In the diagram, it can be seen that the differences between the European countries is very great - everything from
42 in Turkey to 11 in the Netherlands. So the country with the highest use in Europe uses 3.5 times more antibiotics than the country with the lowest!

The level in most of the Nordic region is lower than the European average, with Sweden just above the level in the Netherlands. Nevertheless, the difference between Sweden and the Nordic country with the highest level - Iceland - is as much as over $50 \%$.

\section{Use of antibiotics outside hospitals, 2011}

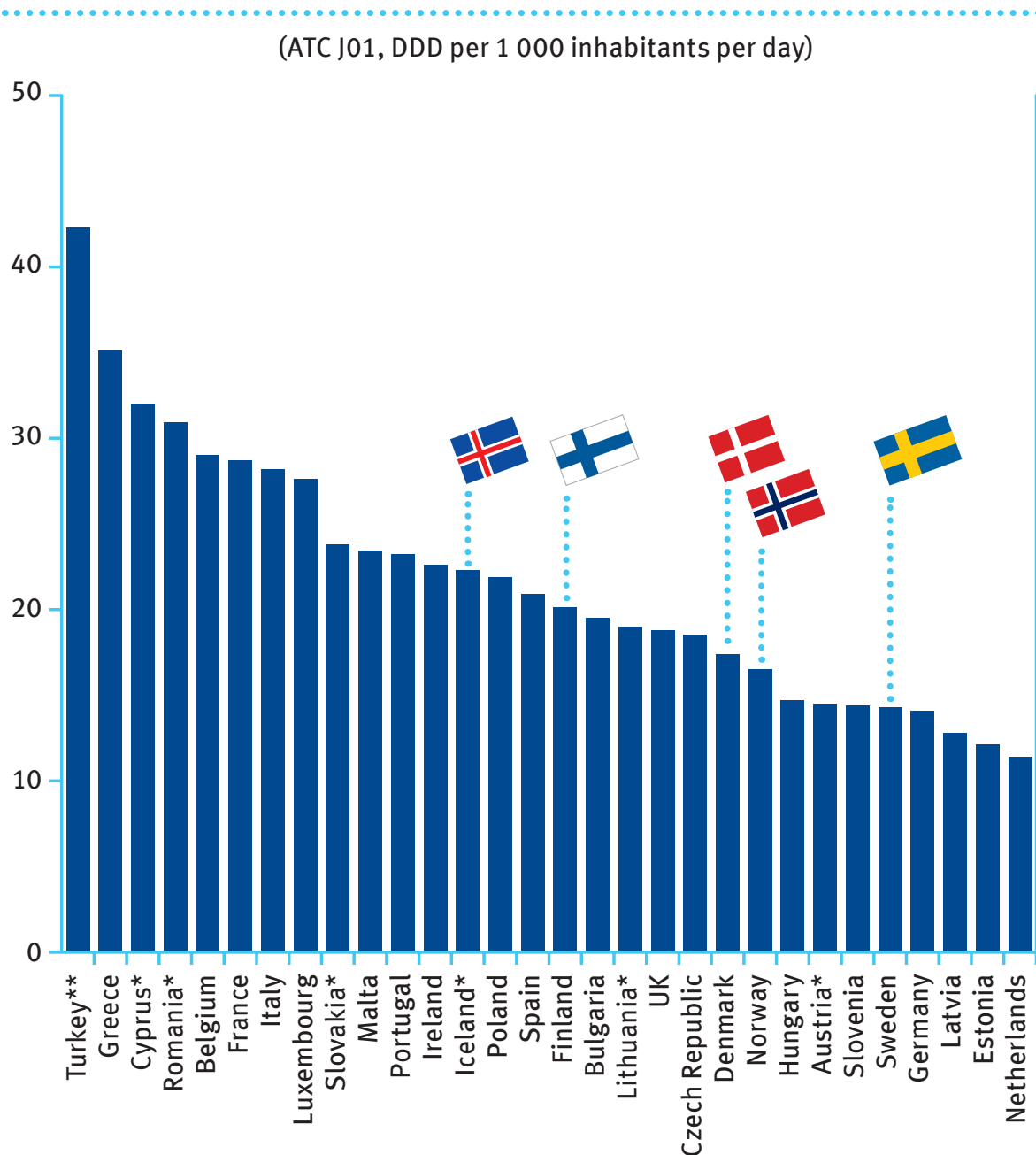

Source: European Centre for Disease Prevention and Control (ECDC), Consumption of antimicrobials of Antibacterials for Systemic Use (ATC group J01) in the community (primary care sector) in Europe, reporting year 2011.

* ECDC note: Figure refers to total consumption, including hospital care.

**Source: The Lancet Infectious Disease, Vol 14 May 2014, Antibiotic use in eastern Europe: a crossnational database study in coordination with the WHO Regional Office for Europe. Figures refer to total consumption, including hospital care. 
A reasonable ambition for the reduction in the Nordic region is to reach the current level in the Netherlands within a five-year period.

Several countries, including Turkey, have adopted plans to reduce their overuse of antibiotics. Another example is India, which adopted the Chennai Declaration in 2012, a five-year plan to combat antibiotic resistance.

In addition to overuse of antibiotics for people, many antibiotics are used in animal husbandry. It is used against bacteria, but also for commercial reasons, to increase the growth of meat. Within the EU, the latter use is no longer permitted, but antibiotics may be given to prevent diseases, and there the limits are rather vague. Sweden is one example of successful reduction of antibiotics for animals. In Sweden, the use of antibiotics for animals in the past six years has been reduced by just over $1 / 3$ to what is probably the lowest level in the EU. This has been done through measures to improve animal husbandry and hygiene. The use in Iceland and Norway is even lower.

Despite common regulations in the EU for how antibiotics are to be given to animals, there are still large differences between the countries. In some EU countries, veterinary surgeons may sell the antibiotics they prescribe. This can lead to more prescriptions and overprescribing, which should be stopped. A ban on veterinary surgeons earning money through the sale of antibiotics should be introduced in the EU.

The difference between the EU countries in terms of the use of antibiotics in animal husbandry is also very great. There are countries that, a year or so ago, used 30 times more antibiotics per $\mathrm{kg}$ meat than the EU country that uses least, Sweden.

One positive example from this year is that the Nordic Council of Ministers has taken the initiative to secure the "One Health" perspective in the Nordic co-operation, by setting up a new working group for cooperation on antibiotic resistance.

Among the direct measures the Nordic countries should take is to improve procedures and hygiene in health care, and the five-year goal referred to earlier to reduce the total use of antibiotics in health care to the current level in the Netherlands.

The EU, WHO and UN should work rigorously so that all countries set goals to reduce overuse of antibiotics for people and animals, and that powerful financial incentives are set up for development of new antibiotics. The Nordic region should show the way in driving this issue.

Even within the framework of the Nordic countries' aid to the developing countries, the issue of overuse of antibiotics should be taken up.

In recent years, measures have been taken in the EU to financially, and in other ways, stimulate innovations in the antibiotics field. However, these are far from sufficient.

There are clearly significant scientific problems in developing new antibiotics. One important reason why no new antibiotics are being developed is probably that the current financial incentives to do so are too weak, because the aim is that the new drugs will be used rarely and thereby generate smaller revenues than drugs that are used often.

Solving the problem of developing new antibiotics will probably require many tens of billions SEK. This money must be set aside by the rich countries. My proposal is therefore that the EU, USA and other rich countries agree to, in the coming 5 years, set aside approximately one-twentieth of a per mille of their GNP as support for development of new antibiotics and rewards for those who 
successfully develop them. They then take over ownership rights for these drugs and can then stipulate conditions for how the countries use the new drugs.

For the Nordic region, this corresponds to approximately SEK 0.5 billion, and for the EU, USA and other rich countries approximately SEK 15 billion, which over 5 years would be approximately SEK
75 billion. How much of this should be granted directly to research and how much should be in the form of a reward/prize to whoever presents new antibiotics must be considered in more detail.

In view of the above proposal, it is proposed that the issue be raised for consideration at a ministerial meeting in autumn 2014. 


\title{
Highly-specialised treatment
}

\section{Proposal 2 Strong co-operation on highly-specialised treatment in the Nordic region}

\author{
A Nordic review group is set up at high level that will \\ strengthen and further develop the Nordic co-operation on \\ highly-specialised treatment in health care.
}

\begin{abstract}
The Nordic countries have many common features, so co-operation on highlyspecialised treatment seems natural. Health care in the Nordic countries is undergoing a significant centralisation. In addition to linguistic and cultural similarities, all the Nordic countries have relatively small populations, and sickness patterns and clinical practices are similar.

Consequently, there are already many good examples of co-operation on highlyspecialised treatment in the Nordic region. However, this work will be consolidated and further developed, so that the cooperation better realises the inherent possibilities to promote efficiency, quality and good use of the economic resources in the countries.
\end{abstract}

In order to consolidate the co-operation and support the countries' strategic assessment of where there is potential for Nordic co-operation, a review group for highly-specialised treatment in the Nordic region should be set up. The review group will support the countries in their continual assessment of where they can create added value by participating in Nordic co-operation on tangible highlyspecialised treatments; an example is through co-operation on purchase of expensive technology and to facilitate the work on launching new co-operation initiatives.

The main task of the review group will be to serve as a forum for regular dialogue between the countries on the needs and opportunities for co-operation initiatives in the area. Each individual country will inform the review group when a new, highly-specialised treatment initiative is being planned. This gives the review group the opportunity to discuss whether Nordic co-operation can create added value for the applicable initiative in cases where there are similar needs - or experiences in the field - in one or more of the other Nordic countries. The individual country ensures that the dialogue in the review group is carried out at such an early stage in the planning phase that co-Nordic cooperation can be started where relevant. Obstacles in the regulatory systems are removed to increase the Nordic cooperation on highly-specialised treatment.

As part of the discussions on relevant cooperation initiatives, the review group will discuss the conditions relating to the implementation of the initiative, including continually identifying which legislative obstacles must be resolved to create a basis for efficient Nordic co-operation on highly-specialised treatment. The review group will also continually discuss what the countries will understand as highlyspecialised treatment. The review group builds further on the experiences that are generated through existing Nordic cooperation projects, including the initiative on highly-specialised treatment within the Nordic Council of Ministers programme on Sustainable Nordic Welfare. 
Decisions on co-operation projects will increasingly be part of the countries' strategic planning of new initiatives, and will be anchored close to the policy level. Consequently, the members of the review group will be of high level. The review group will be linked to the Nordic Council of Ministers for Health and Social Affairs, and will be mandated by the Council of Ministers. 


\section{Rare diagnoses}

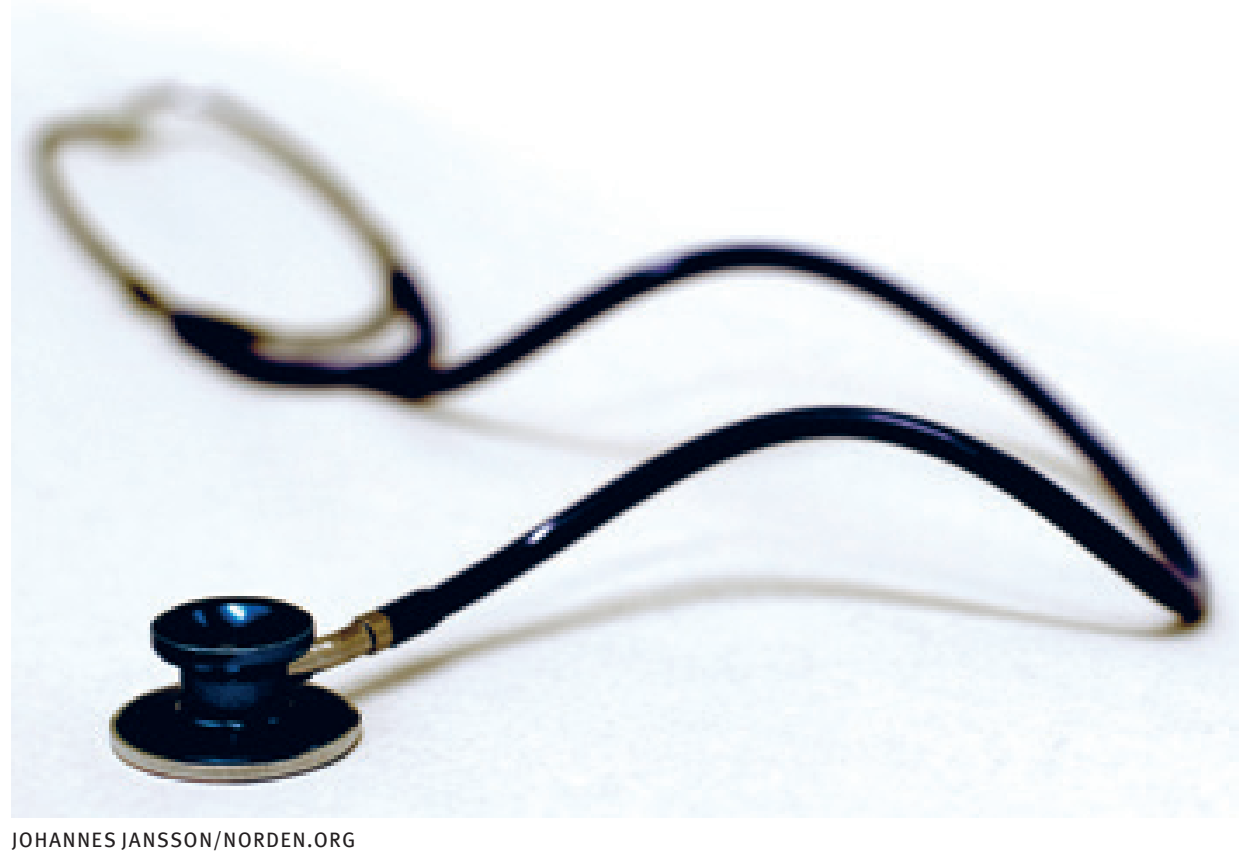

Proposal 3 Set up Nordic network on rare diagnoses

\section{A Nordic network on rare diagnoses will be set up.}

The Nordic countries' populations are relatively small, and so it is a challenge to get a sufficiently large population base for developing and maintaining expertise when it comes to initiatives for people with rare diagnoses. However, the Nordic countries have a total population of approximately 26 million, and the common features of the countries mean that Nordic co-operation feels natural, something that will strengthen the knowledge environments of the individual country and measures for people with rare diagnoses.

For several years, the Nordic countries have been initiating various co-operation projects on rare diagnoses, for example the co-operation on exchanging information via Rarelink. These co-operation initiatives will be developed, but it is also important to strengthen current and new joint Nordic initiatives and to improve coordination of them.

Consequently, the countries should set up a Nordic network for forward-looking cooperation in the area of rare diagnoses, which can secure the continuity that is required in the work. In this way, the Nordic co-operation in the area will have greater effect for the relevant subject environments and the authorities in the countries - and ultimately also for the inhabitants. 


\title{
Register-based research
}

\section{Proposal 4 A Nordic virtual centre is set up for register-based research}

\author{
The Nordic research co-operation on data registers, \\ biobanks and clinical intervention studies will be \\ strengthened by facilitating access to our unique Nordic \\ data sources in research. A model for mutual recognition \\ of ethical reviews of Nordic research projects will be \\ introduced. Such co-operation can help to develop \\ research, business and welfare in the Nordic region.
}

The Nordic region is a goldmine for population-based research because of access to stored data on individuals in administrative registers of personal information, and biobanks. This information has been collected over a long time, and often covers the entire Nordic population. The similarities between the health and welfare systems in the Nordic countries, and our personal identification numbers, give good conditions for comparative studies and analyses in the Nordic region. Together, the Nordic region has 26 million inhabitants, which comprise a population base that enables studies of unusual diseases.

Greater use of register data in research can help to prevent diseases, find more efficacious drugs, and further develop treatment methods, for example in individualised health care. Measures to strengthen the Nordic co-operation in this area will increase the number of clinical studies and thereby help to give a better knowledge base for political prioritisations in the welfare sector and increase the competitiveness of business. In addition, the Nordic region would strengthen its brand as an attractive region in which to carry out top-level research.

However, in order to use the data available, the following measures are needed:

The countries must remove practical, legal and ethical obstacles to common use of date for research. National owners of data with responsibility for administrative registers of personal information, biological data (health care quality registers, biobanks) or similar, should cooperate to simplify the use and transfer of data over borders.

A model for mutual recognition of ethical reviews of Nordic research projects will be introduced.

Furthermore, the countries should work to facilitate the use of personal data in cross-border research under applicable legislation, for example through changed practice. The countries should also investigate the possibilities for Nordic synergy, in particular in relation to forthcoming European legislation in these areas. 
The research infrastructure will be strengthened in these areas. NordForsk and the research councils (or equivalent) should support the development of technical solutions that enable safe transfer, storage and access to personal data and research data, including across borders. In addition, simpler co-ordination of data should also be enabled to build up common Nordic data sources/registers. In addition, NordForsk and the research councils should finance research and training at Nordic level to utilise the common Nordic data sources. Certain preparatory measures have already been taken by NordForsk.

When practical, legal and ethical obstacles are removed, initiatives on research infrastructure and research should be further developed to set up a Nordic virtual centre for register-based research. Such a centre would enable researchers and businesses to use our unique data registers and biobanks as a common Nordic resource, by comprising a cooperation platform for national players and continuing the work to remove existing obstacles to cross-border research. This type of common distributed Nordic resource can be co-ordinated by NordForsk, for example based on a model similar to that of the Nordic e-Infrastructure Co-operation ( $\mathrm{NeIC}$ ), in close collaboration with central national players. 


\title{
Public health and inequalities in health
}

\section{Proposal 5 Increased co-operation on initiatives to improve public health}

\author{
The Nordic countries should increase the exchange of \\ information on public health issues, particularly the use of \\ tobacco and misuse of alcohol.
}

\begin{abstract}
Tobacco and alcohol are two socially accepted stimulants in much of the world, even though they contribute to poorer public health. The Nordic region generally has lower alcohol and tobacco consumption than the rest of Europe, but can work even more actively to reduce tobacco- and alcohol-related diseases, not least cancer diseases. The Nordic countries should decide to exchange experiences in the public health area more frequently, particularly in terms of measures in the alcohol and tobacco policies.
\end{abstract}

\begin{abstract}
Much is to be done to improve public health in the Nordic region, despite the strong increase in life expectancy and, as mentioned in the introduction to the report, despite what also seem to be healthy years added to life. The two most important areas, and which can also be influenced by political decisions, are the use of tobacco and the misuse of alcohol.

A comparison of the table showing life expectancy in the Nordic countries and the table showing consumption of alcohol and tobacco indicates an association.
\end{abstract}

\section{Life expectancy}

\begin{tabular}{|c|c|c|}
\hline & 2012 & Increase (yrs) 1960-2012* \\
\hline Iceland & 82.9 & 9 \\
\hline Sweden & 81.7 & 9 \\
\hline Norway & 81.5 & 8 \\
\hline Finland & 80.6 & 12 \\
\hline Denmark & 80.1 & 8 \\
\hline $\begin{array}{l}\text { Nordic } \\
\text { average }\end{array}$ & 81.4 & 9 \\
\hline
\end{tabular}




\section{Men who smoke daily}

(\% of men aged 15 and older)

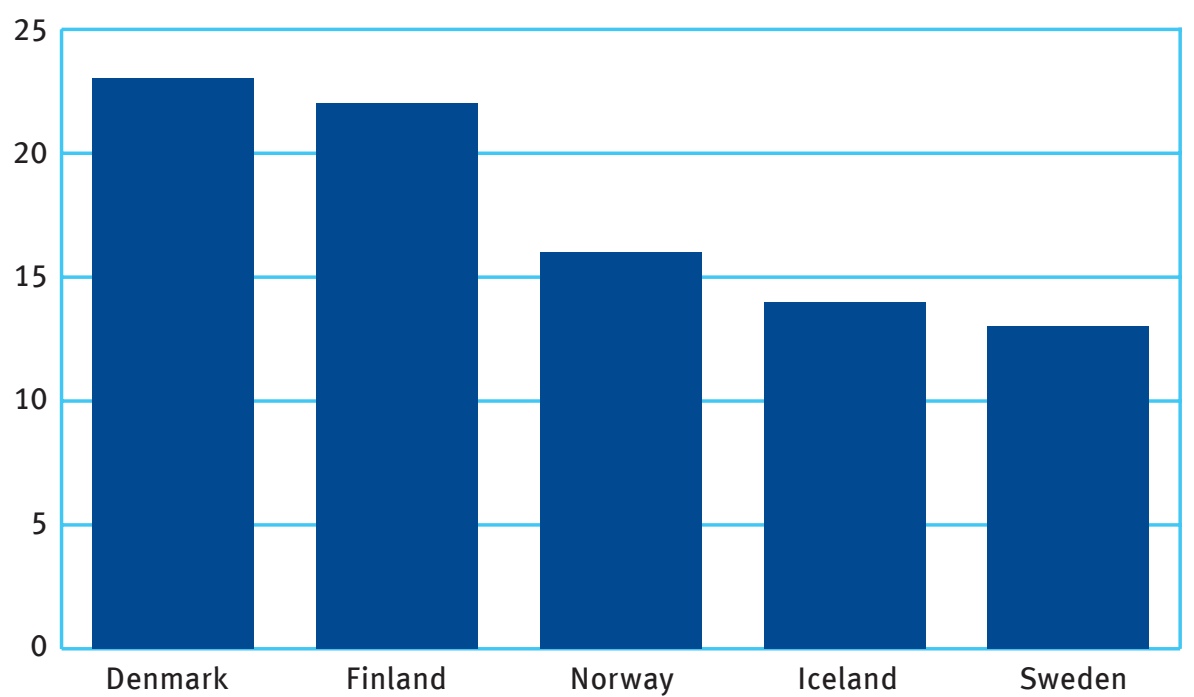

Source: Health Statistics in the Nordic Countries 2013 (NOMESKO), p. 44, Table 3.1.2 Percentage of daily smokers by sex.

For DK age 16+, FIN 15-64 yrs, NO 16-74 yrs, IS 15+, SVE 16-84 yrs.

\section{Sales of alcoholic beverages in litres of $100 \%$ pure alcohol per capita}

(15 years and older)

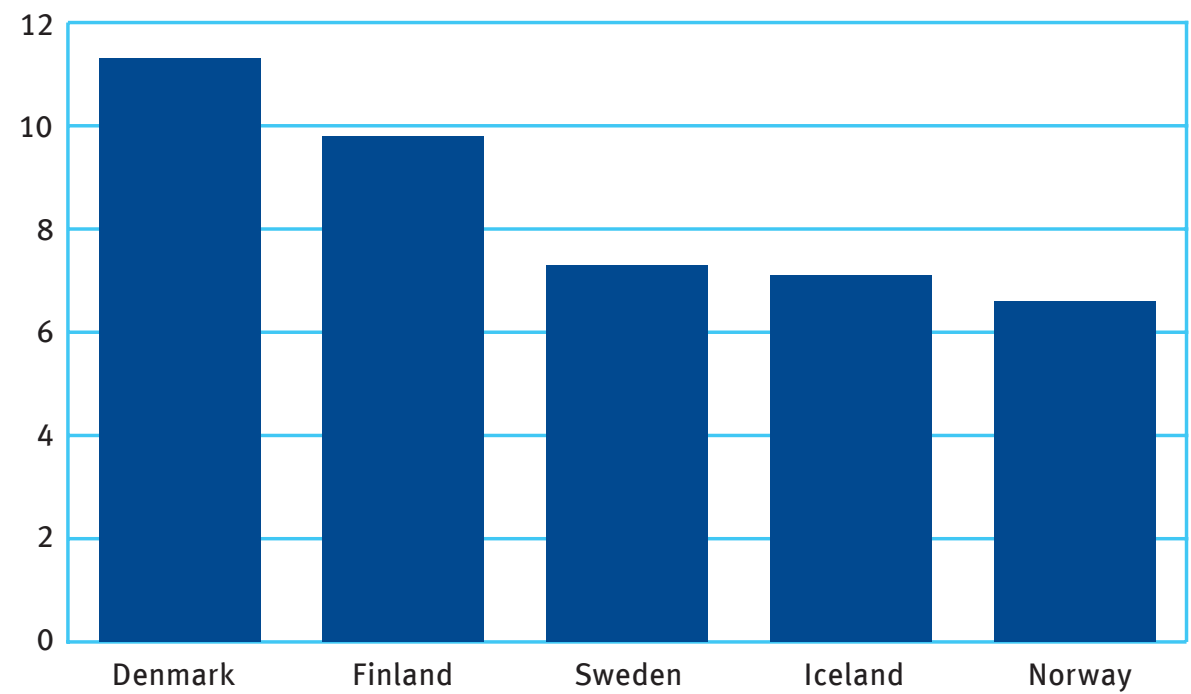

Source: Health Statistics in the Nordic Countries 2013 (NOMESKO), p.47, Table 3.1.4. Sales of alcoholic beverages in litres of $100 \%$ pure alcohol per capita, 15 years and over.

For FIN \& NO, figures are from 2011, DK and SE from 2010, and IS from 2005. 


\section{Self-reported obesity, men}

aged 15 and older (\%)

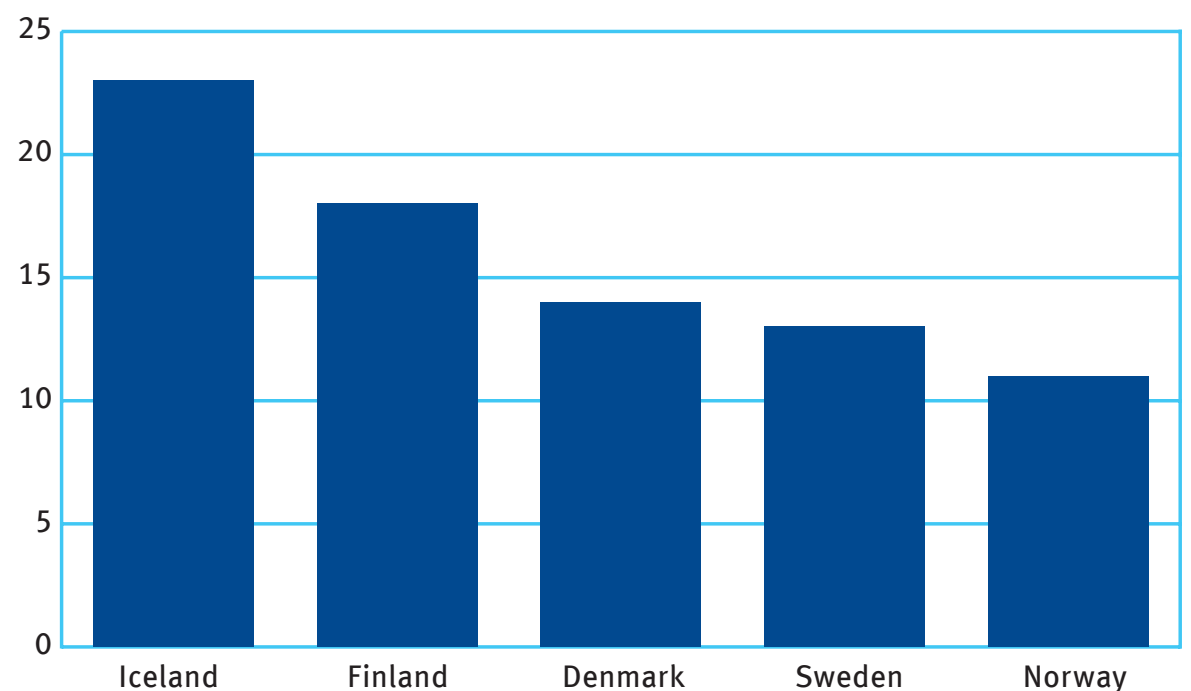

Source: Health Statistics in the Nordic Countries 2013 (NOMESKO), p. 44, Table 3.1.1: Overview of self-reported obesity, inhabitants aged 15 and over.

Obesity means BMI>30. For NO, from age $16+$

One example is the number of lung cancer cases per million inhabitants, which varies greatly between the various countries. In 2011 the total number of cases in Denmark was just over 800 and in Sweden just less than 400 .

The Nordic countries should decide to exchange experiences in the public health area more frequently, particularly in terms of measures in the alcohol and tobacco policies. One aim should be, using the various countries' experiences, to reduce alcohol consumption and tobacco consumption. Countries and areas with low age limits for purchasing alcohol and high per mille limits in traffic, should learn from other countries' experiences. 


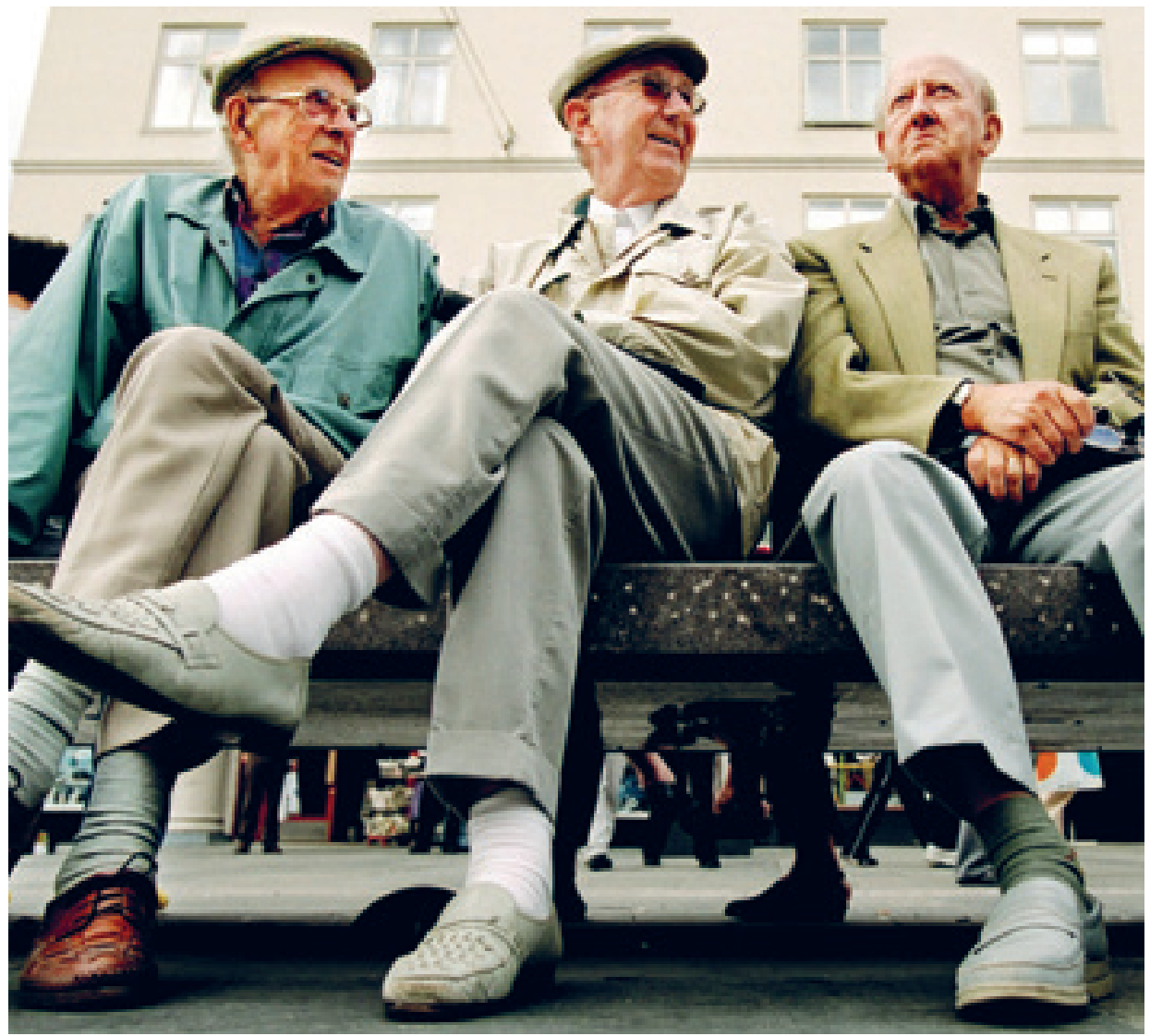

KAREN BEATE NøSTERUD/NORDEN.ORG

\section{Proposal 6 A Nordic public health policy platform to reduce inequality in health}

\section{A Nordic public health policy platform will be set up with the task of developing proposals for Nordic projects and activities aimed at reducing inequality in health.}

In the Nordic region, public health has been developing positively for many years. The Nordic welfare model, with relatively small differences in economic standards, gives good conditions for evening out differences in health. Nevertheless, the health differences in the Nordic region are significant between people with long education and high income and those with short education and low income. A major challenge facing Nordic welfare is all the chronic disorders caused by lifestyle. Better health brings many societal benefits: reduced sickness and mortality, better quality of life, and greater well-being for all Nordic inhabitants. It is therefore high time to reverse the trend of increasing differences in health, through a pooling of forces at Nordic level.

A Nordic public health policy platform will be set up with the task of formulating proposals for Nordic projects and activities aimed at reducing inequality in health. The co-operation will mainly focus on preventive measures to reduce inequality in health by reviewing various lifestyle factors such as alcohol, tobacco, 
diet, food, and exercise. One example of an activity can be a campaign to combat the new public health disease, obesity. The group should also be prepared to work with issues that the Nordic Council of Ministers proposes.

The platform should comprise participants with political mandates, practitioners, researchers and officials. A cross-sectoral perspective will be a guiding light for the platform, which will also interact with existing working groups, networks, institutions, etc. at the Nordic level.

\title{
Patient mobility
}

\section{Proposal 7 Patient mobility within the Nordic region}

\author{
At next year's ministerial meeting, the Nordic countries \\ should evaluate the effects, on the patients, of the Nordic \\ countries' recently-adopted implementation of the EU \\ patient mobility directive, and try to further extend the \\ right to treatment in any of the other Nordic countries.
}

Naturally, it is valuable if patients can choose care provider. This applies not only within the individual's own municipality and own country, but also in one of the other Nordic countries. There is also a value in being able to seek and, if necessary, receive treatment in some other European country. The EU has adopted a directive on patient mobility that involves the EU countries and Norway, Iceland, and Switzerland.

The Nordic countries have each adopted laws to implement the directive. The various laws differ.
The Nordic countries are permitted to introduce a greater degree of choice for Nordic citizens, providing this does not mean a worse level for other EU citizens than that stipulated in the EU directive.

After only a few months, it is not yet possible to assess how the Nordic countries' introduction of the directive has affected the real choice of the citizens. It is therefore proposed that greater choice be assessed by the ministers after a further one year's experience of the implementation. 


\section{Health and technology}

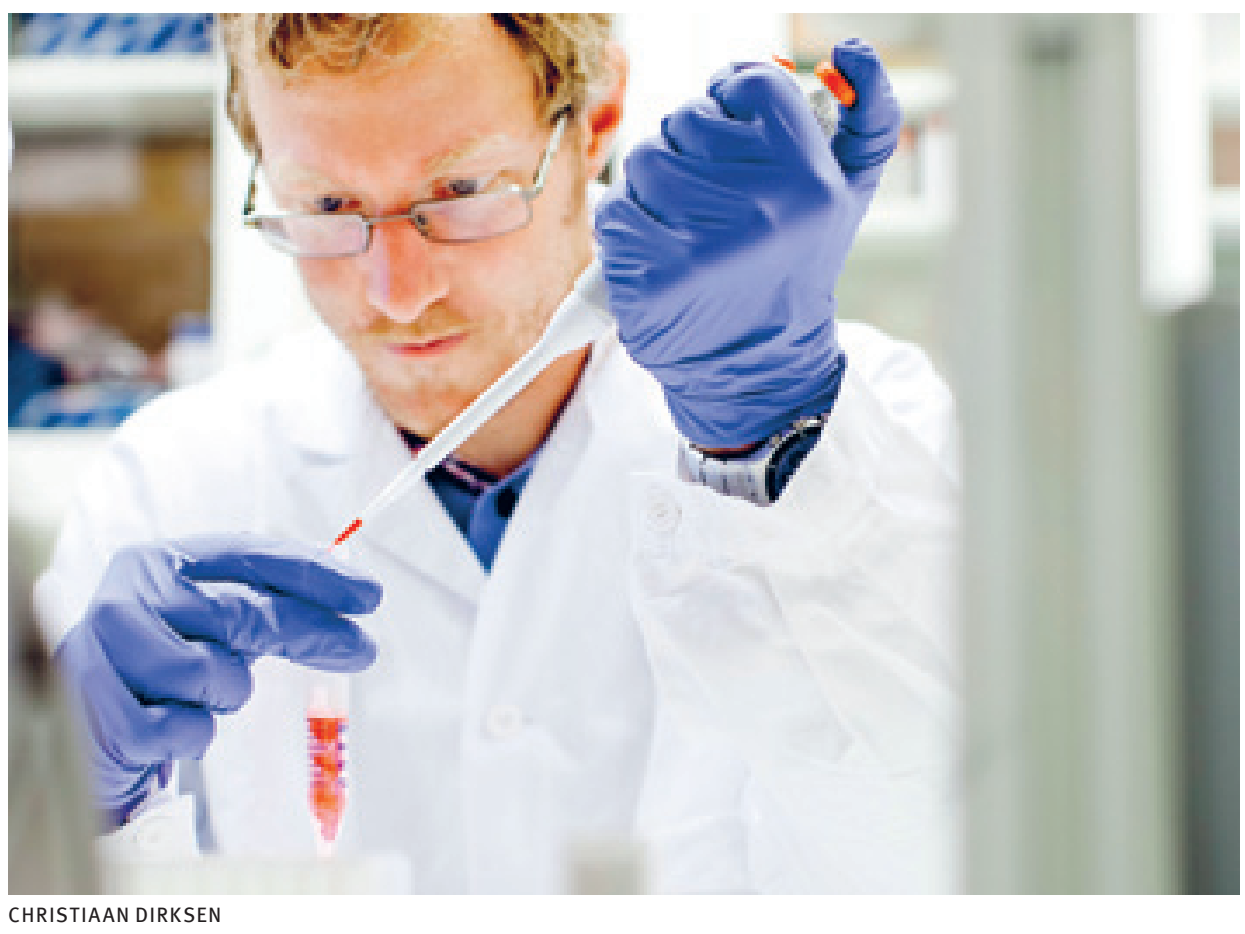

\section{Proposal 8 Strengthened co-operation on welfare technology}

A common Nordic definition of welfare technology is developed. A common Nordic market is strengthened by harmonising standards for welfare technology products and by developing common guidelines. The inclusion of users in the development work in welfare technology is promoted through dissemination of information, good examples, and common guidelines.

A definition of welfare technology is, for example, knowledge and use of technology that can contribute to greater safety, activity, participation and independence for people with disabilities and their relatives, including elderly people. However, according to a broader definition, it concerns technical solutions that make life easier and increase participation for much larger groups of citizens. There can be many forms: care, aids, solutions in dwellings, rehabilitation, special education, accessible workplaces, or individual-adapted communication. Universal design is a concept through which an aim is to build an easily accessible and sustainable society for all. The work is often cross-sectoral and it is important to see the health and social sectors as one and the same whole. 


\section{A Nordic definition of welfare technology}

Welfare technology is highly prioritised throughout the Nordic region, but the countries have chosen to work with the theme from slightly different angles. The Nordic countries have exchanged experiences and information about welfare technology in recent years, and co-operation is taking place, for example on innovations and how they can be implemented more efficiently. The Nordic Council of Ministers has also started a project that is building up Nordic cooperation at municipal level. However, a common, generally accepted and coNordic definition of welfare technology is still lacking; this would facilitate the co-operation and give it greater focus. Consequently, development of a Nordic definition of the area is proposed.

\section{A common Nordic market for standards for welfare technology products}

Demand for welfare technology products is higher than ever, and hundreds of new jobs have already been created in the sector. However, in terms of development of new solutions, an aim could be a much more uniform market in the Nordic region. If the countries had similar standards for new products, particularly in the areas that are already internationally strong, demand and volume would immediately increase. Sweden, for example, is leading the EU cooperation on standardisation of personal security alarms.
Welfare technology solutions also require a high level of co-operation between the public and private sectors. It is therefore important to include standards in tender documentation in public procurement in an identical way throughout the Nordic region. The Nordic co-operation could, at best, promote the activity within the Nordic region, but could also lead to a competitive advantage on the global market. Consequently, a common Nordic market for standards for welfare technology products is proposed.

\section{Users will be included in development work in welfare technology}

Another aspect in the co-operation on welfare technology is to engage in the work the people who themselves use new technology. New technological solutions often enter the private sphere, in view of new design of dwellings or individualised technology. It is important to be open to ethical debate and to process personal obstacles and attitudes, both in those who use new technology and in those who work with it. The Nordic region could lead the way in including users in the development work. It is important to work locally, usually at municipal level, and co-operation is needed just as much at national level. The Nordic cooperation could focus on dissemination of information, best practice and common Nordic guidelines for including the users. 


\title{
Proposal 9 Extended co-operation on e-Health
}

\author{
Co-operation on e-prescriptions should continue with \\ Nordic ownership. A Nordic health library (online) is \\ created. A Nordic search tool, "My Patient" is developed.
}

E-health means practising health care using electronic processes and communication. The concept may comprise a series of services, such as e-journals, telemedicine and health information for patients. E-health will be seen as a holistic modernisation activity instead of solely new technological solutions.

\section{Continued co-operation on e-prescriptions in the Nordic region} The Nordic countries have participated actively in EU co-operation on e-Health, such as the epSOS project. The aim has been to develop the European e-Prescription, which facilitates the citizens' mobility over national borders despite their need for medication. The EU project is now completed, but Nordic cooperation should get under way. The Nordic countries also co-operate on common structures and terminology in patient records, indicators for comparing and measuring development work in e-Health, and reviewing legal obstacles to crossborder activities.

\section{A Nordic health library (online)}

A relatively new idea, most advanced in Norway, is a health library that works online. The library provides service for healthcare professionals in the form of good examples, instructions for treatment procedures, information databases and journals. However, most of the content is open to all citizens. A corresponding function is found in other countries, but the purpose and reference frameworks vary. It is a common trend in the Nordic region that patients are to have easier access to information about quality and medical results and online service that is aimed directly at the citizens. Co-operation on the health library should be cost-effective, give all care personnel access to scientific information, and also help to increase citizens' knowledge and responsibility for their own health.

\section{New Nordic co-operation on the "My Patient" search tool}

Within the framework of the online library, the concept of a "My Patient" tool can be developed. It concerns setting up an intelligent search function that offers support to the doctor in individual assessments of the patient's care needs. In practice it works as follows: the doctor enters the patient's symptoms without using the patient's identity, and receives in response a number of patients with the same symptoms and with a note on proposals for care. Most countries have developed data collection on patients and health care to such an extent that a similar search function could be developed. Such a search function would increase patient security and thereby help to increase trust in the health care. 


\title{
Psychiatry
}

\section{Proposal 10 Stronger Nordic co-operation in the psychiatry area}

\author{
The Nordic co-operation on psychiatry is strengthened by \\ an annual Nordic summit meeting within the psychiatry \\ field, greater Nordic collection of knowledge, and exchange \\ of experience on models of best practice.
}

When people are affected by psychiatric illhealth, it often has major consequences for people, both for the individual concerned and the relatives. An increasing number of people in the Nordic region are diagnosed with a psychiatric disorder. This applies in particular to children and young people, and applies to non-psychotic disorders. Consequently, the Nordic countries are experiencing that psychiatric ill-health comprises a growing proportion of the total burden of disease, and it uses up many resources in health care, medical care and social care. Consequently, increasing mental health problems and psychiatric disorders have great societal consequences for the Nordic countries for example, because psychiatric problems are also a major cause of sick leave, longterm unemployment and early retirement.

There are no systematic statistics of early retirement caused by psychiatric disorders in the Nordic region, and there are reasons to look more closely at the area. However, a survey carried out in 2009 by the Finnish FPA institute shows that, every day, five Finnish young people are placed on early retirement because of a psychiatric disorder, and that nearly half of all people placed on early retirement in Finland have a psychiatric disorder. This was a total of 117,600 people in 2009 . Half of these early retirements were caused by depression. Between 2004 and 2009, the proportion of men on early retirement after a psychiatric diagnosis grew by $60.5 \%$ and the proportion of women by $42.1 \%$. The greatest increase was for people under 30. Similar tendencies, particularly among young people under 30 , can be seen in the other Nordic countries.

\begin{abstract}
A psychiatric diagnosis has also been stated as being the leading cause of a young person being granted early retirement of any type. This applies in over half of the cases in all Nordic countries, and in up to $80 \%$ of the cases in Denmark and $76 \%$ in Sweden.
\end{abstract}

The Nordic governments recognise the need to equate psychiatric disorders with physical disorders. During these years, the range of treatments and treatment methods in psychiatry have been developed greatly, with focus on for example preventive work, a more coherent treatment and greater involvement of the individual, reduced use of coercion, de-stigmatisation, and the individual patient's opportunity to be completely or partly healthy after the disorder. Focus is also increasingly on the health-based inequality that people with psychiatric disorders experience - people with psychiatric disorders suffer more from physical disorders than the rest of the population.

At the same time, psychiatry is an area that is characterised by little or lack of evidence. More research and development is required to enable a real quality lift in 
the psychiatric treatment. There is a need to develop and disseminate evidencebased methods so that the treatment is more based on the best knowledge that is available at the time.

When we face these challenges - and in view of the many common features of the Nordic countries in terms of societal structure and social development - it is a given that the Nordic co-operation on psychiatry will be strengthened so that the countries can derive greater benefit from the experiences of their Nordic neighbours. This co-operation can focus on:

- Greater exchange of experiences on models of best practice so that experiences in one Nordic country can benefit other inhabitants in the Nordic region, for example by starting to use new treatment methods after these have been tested in another Nordic country or by greater co-operation on testing new treatment methods.
- Greater Nordic collection of knowledge through extended research cooperation and increased co-operation on measurement of quality and development of quality indicators. In 2011, Nordic co-operation on quality measurements in psychiatry found that the Nordic countries have outstanding opportunities for quality measurement, partly due to the countries' successful quality registers. This co-operation can continue and be strengthened.

- An annual summit meeting on psychiatry. A summit meeting on psychiatry that is held every year will be a natural forum for exchanging experiences and disseminating psychiatric knowledge and results (see proposal above). A psychiatry summit meeting involving decisionmakers, researchers, practitioners, user organisations, etc. will also be able to help direct focus towards and help with de-stigmatisation of people with psychiatric disorders. 


\title{
Health preparedness
}

\section{Proposal 11 Greater mandate for co-operation within the health preparedness area}

\author{
The Nordic public health preparedness group (the Svalbard \\ Group) will have a greater mandate. All aspects within the \\ framework of co-operation on health preparedness will be \\ included.
}

In June 2002, the Nordic Ministers for Health and Social Affairs signed a framework agreement for co-operation on Nordic health preparedness. The aim of the agreement was to use preliminary measures to develop the Nordic countries' mutual preparedness to prevent and manage emergencies and disasters. The informal working group (the Svalbard Group) was given the task of developing the co-operation. In addition to managing the consequences of conventional accidents, the agreement also considers in particular incidents involving biological and chemical substances, and the need for specialist knowledge in accidents involving radioactivity and terrorist attacks.

In some parts, the work of the Svalbard Group has been very successful, particularly in terms of network co-operation. However, the working group has had certain difficulties in carrying out its tasks, mainly because there are many authorities/ institutions involved at national level, with different perspectives and goals. In recent years, focus has shifted from the original mandate to several other areas relating to disasters, such as trauma care, ambulance service and medical care services.
It is important to broaden the health preparedness from the perspective of holistic safety. New threats are growing rapidly, not least using through the digital development. For example, preparedness ahead of various cyber-threats requires intensive co-operation between various sectors at national, Nordic and international level.

The mandate also needs to reflect the work that is actually taking place. The constantly increasing number of serious incidents that have occurred in recent years strengthens the motivation for even closer co-operation. It is very important that the new mandate contains a clear distribution of responsibility for the co-operation with the Svalbard Group and authorities/ institutions in the Nordic countries.

Future co-operation in health preparedness can, for example, concern joint research and development, training, purchasing, and contingency stocks. Some concrete examples are joint air medical training programmes and common resources for airborne medical evacuation. 


\section{Pharmaceuticals}

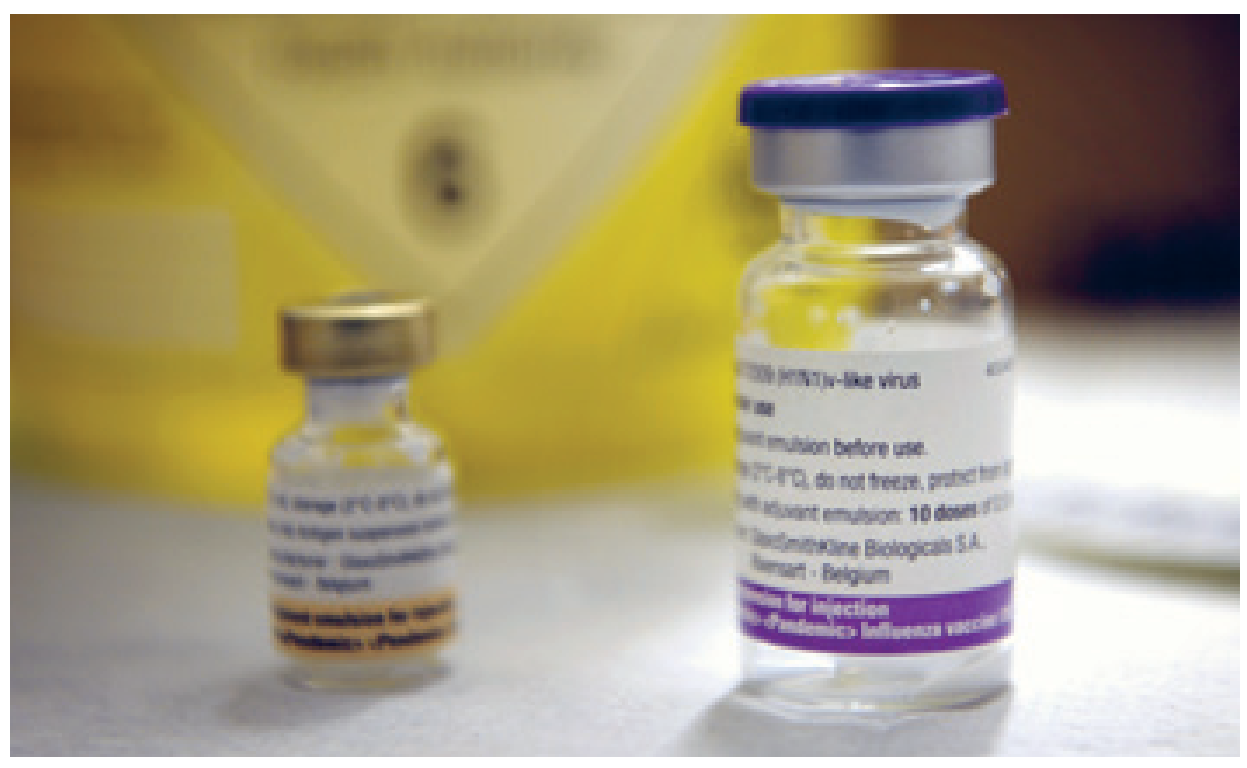

JOHANNES JANSSON/NORDEN.ORG

\section{Proposal 12 Extended Nordic pharmaceutical co-operation for greater cost-effectiveness and safety}

The Nordic co-operation in the pharmaceutical area is extended by setting up a joint pharmacy for unusual drugs, greater co-operation on rare drugs, and through greater exchange of information on purchasing agreements and on implementation of new drugs.

Drugs account for a large proportion of the countries' health care costs. The Nordic countries all lie below the OECD average for drug costs per inhabitant or as a proportion of GNP. In 2011, drug costs in the OECD countries accounted on average for virtually one-sixth of the countries' health care costs, which makes it the third biggest cost item in the health care budget after hospital care and outpatient care.

Like all other countries, the Nordic countries are challenged by the fact that new - and often very expensive - drugs are introduced to the market, something that is often of great benefit for the patients but that puts the countries' health costs under pressure. At the same time, the geographical proximity and common language mean that differences in the countries' implementation of new drugs are easily exposed in the various national media, which can put pressure on the health care authorities to follow decisions made in neighbouring countries.

In a global context, the Nordic countries are in themselves small markets for the pharmaceutical manufacturers particularly when it comes to drugs for treatment of rare diseases. Because of this, the possibility for extended 
Nordic co-operation in the area has been discussed several times under the auspices of the Nordic Council of Ministers - for example, on Icelandic initiative in 2008 and at the ministerial meeting during the Danish presidency in 2010. However, the discussions have not led to any concrete results, because of differences in the countries' organisation in the pharmaceutical area, which for example leads to different pricing and different structures for decision-making.

However, there is still opportunity to expand the Nordic co-operation in the pharmaceutical field, which can benefit the inhabitants of the Nordic region. Greater exchange of experiences on the conditions and prices applying in the countries in connection with purchases are expected to strengthen the position of the countries in future negotiations.

There is also a need to extend the exchange of experiences on implementation of new drugs, something that could, at a later stage, be developed into tangible co-operation on assessment of new drugs. The co-operation is established between the relevant bodies in the countries. Regardless of the obstacles to general joint purchasing, it would even be appropriate to expand the co-operation to maintain an appropriate store of unusual drugs in preparedness. This applies to diseases that occur rarely in the Nordic countries (e.g. snake poison, diphtheria and botulism) and where it is not appropriate from an efficiency perspective to build up stocks at national level.

The co-operation can first result in setting up a Nordic pharmacy for unusual drugs, and can then be expanded to cover contingency products, i.e. vaccines and antitoxins that are rarely used, but for which the Nordic countries should have a contingency stock that can be used in emergency situations (such as vaccine against poxes). 


\title{
Exchanges for officials
}

\section{Proposal 13 New exchange of Nordic officials - pilot project}

\author{
Increased exchange of Nordic officials in the health area \\ will be set up. More officials in the ministries will be given \\ the opportunity for short exchanges to create more and \\ better networks that will increase Nordic expertise and \\ competitiveness.
}

The current Nordic agreement on exchange of officials was founded in 1979, and gives public employees the opportunity to learn about the administration in a different Nordic country, including the Faeroes, Greenland and Åland, to that in their home country for a short or long period. The exchange of officials is a textbook example of Nordic co-operation and has, over the course of the years, been rated very highly. It should be noted that the exchange does not require any mutual exchange of workplace between two employees, and that the participants are on salaried leave. The aim of the exchanges is to learn about conditions in neighbouring Nordic countries, thereby extending Nordic co-operation, and helping the Nordic public authorities and the participants themselves to develop positively.

Unfortunately, it can be observed that far too few officials take part in exchange service. Only 47 people participated in exchange service in 2013 and, of these, only a few were from any ministry. It is primarily authorities of various types that send their employees to neighbouring countries.
By improving the conditions for better contacts between responsible ministries, a supplementary agreement to the current service agreement is therefore proposed. The initiative should be seen as a pilot project (3 years), and the target group is officials who work with health issues in the ministry concerned. The objective is to create more and better networks in and between the relevant ministries in the Nordic countries to increase Nordic expertise and competitiveness. In view of this, a shorter exchange service of one to two weeks is proposed, where focus will lie on building networks, thereby contributing to better communication and exchange of experiences between the countries. Today, the period for exchange service is between one and twelve months, which in itself can be an obstacle for many employees and employers.

Shorter periods should therefore enable more officials to take part in the programme. Funding of the project should be charged to the Nordic Council of Ministers budget. 


\title{
National experts in the EU
}

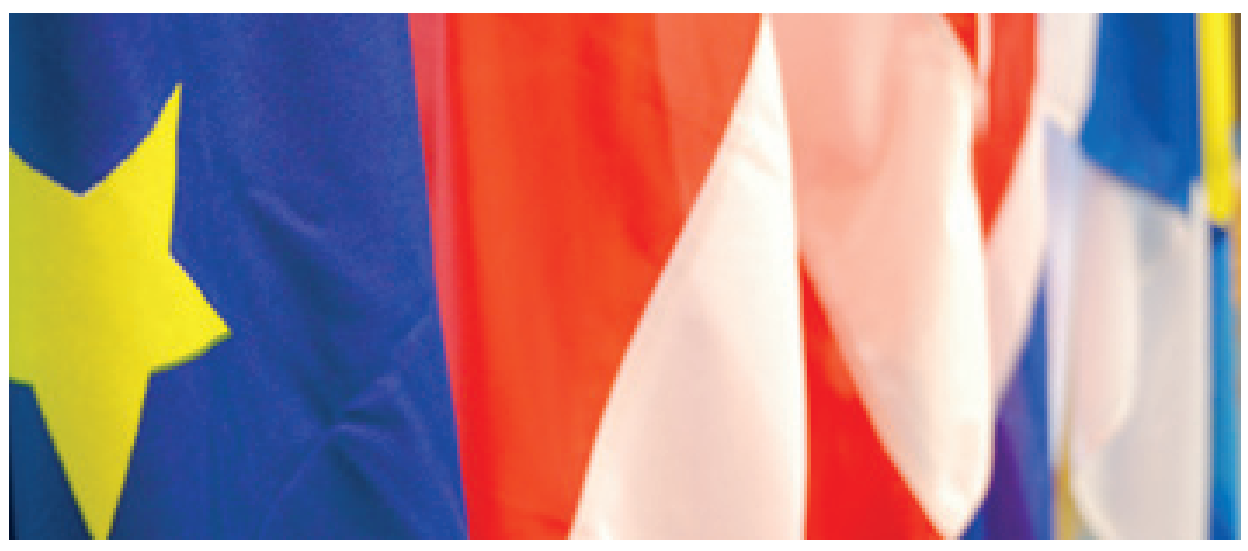

SILJE BERGUM KINSTEN/NORDEN.ORG

\section{Proposal 14 Nordic co-operation on national experts in the EU Commission}

\author{
New informal co-operation on placement of national \\ experts in the European Commission will be initiated in the \\ social and health area
}

The Nordic co-operation is based on common values that form the foundation of the Nordic welfare model. Today, the welfare state is perceived as being under pressure, not least against the background of the demographic development and the economic crisis. Consequently, the countries must act together to meet the challenges. In view of this, a new Nordic informal co-operation on placement of national experts in the European Commission in the social and health area (DG EMPL and DG SANCO) is proposed.

All countries (including the EEA countries) send experts to EU institutions. At present, for example, Sweden has approximately 30 experts in total, covering all policy areas except the social and health area.

A national expert in the Commission increases influence over ongoing processes. The expert can, for example, influence the formulation of a proposal and spread information informally, and is thereby a major asset for the home country. Informal co-operation between the Nordic countries could mean a better and more even placement of national experts, and thereby a better use of the country's resources. It should be more efficient to have Nordic experts evenly spread in various units than many experts with the same/similar view in one unit. A national expert at the Commission means a relatively large cost for a ministry, which limits the countries' opportunities for more influence at an early stage. The expert receives salary from the employer (ministry or authority) and costs are reimbursed by the EU institution (expenses and reimbursement for travel to and from the place of service).

A first stage in the new co-operation can be that the Nordic Committee of Senior Officials for Health and Social Affairs, 
ÄK-S, is informed about which national experts serve in the Commission from each country. Then the international secretariat at the Nordic ministries for health and social affairs should meet regularly to discuss planning of the informal co-operation. 


\section{norden}

Nordic Council of Ministers

Ved Stranden 18

DK-1061 Copenhagen K

www.norden.org

\section{The Future Nordic Co-operation on Health}

Bo Könberg has written an independent report - The Future Nordic Cooperation on Health. The report, which contains tangible proposals for how the Nordic co-operation can be developed and strengthened in the next five to ten years, was presented for the first time in conjunction with the meeting of the Nordic Ministers for Health and Social Affairs in Iceland on 11 June 2014.

Bo Könberg is a Swedish MP representing the Liberal Party. He was Minister for Health and Social Insurance 1991-1994, and led the work on the Swedish Pension Reform. He has participated in a number of Swedish inquiries on welfare issues, including the Ädel Reform and Charges for Medical Care.

The report is part of the Nordic Council of Ministers "Sustainable Nordic Welfare" programme, one of the Council's major initiatives in the period 2013-2015. www.norden.org/welfare 